\title{
Understanding Information Use in a Multidisciplinary Field: A Local Citation Analysis of Neuroscience Research
}

\section{Marian A. Burright, Trudi Bellardo Hahn, and Margaret J. Antonisse}

\begin{abstract}
Assessing the information needs of a multidisciplinary academic community presents challenges to librarians managing journal collections. This case study analyzed the literature used by the neuroscience community at the University of Maryland to determine the following about the publications they cited: their type, their discipline, and how recent they were relative to the citing publication. The authors searched the ISI Science Citation Index and Social Sciences Citation Index to identify the publishing, citing, and coauthoring patterns of both faculty and graduate students to inform library decisions about collecting journals and other types of literature.
\end{abstract}

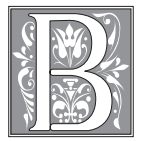

uilding a useful library collection to support research and teaching, while staying within budgetary limits, requires a deep understanding of faculty and students' specific information needs. The challenge of assessing information needs is particularly great when the target community is multidisciplinary and dispersed throughout many academic departments. At the University of Maryland, one such multidisciplinary group is neuroscientists, who are identified through their affiliation with the Ph.D.-granting pro- gram called Neuroscience and Cognitive Science (NACS). ${ }^{1}$ On the College Park campus, NACS membership is composed of seventy-eight faculty members and twenty-seven doctoral students from different departments. This study sought to identify the publication and citation patterns of those NACS members actively engaged in neuroscience research. We identified the literature that the NACS community used with citation analysis methodology. Although we acknowledge the broader meaning of "use" to include means other than citing behavior, "use" of

Marian A. Burright is the Collection Management Librarian for Life Sciences at the University of Maryland Libraries; e-mail: mburrigh@umd.edu. Trudi Bellardo Hahn is the Manager of User Education Services at the University of Maryland Libraries; e-mail: thahn@umd.edu. Margaret J. Antonisse is the Undergraduate Studies Librarian at the University of Maryland Libraries; e-mail: mja@umd.edu. Funding for this study was provided by grants from the Society for Neuroscience and the University of Maryland Libraries. The authors would like to thank Gary Phillips (UMCP) for his assistance with the data processing and Scott Burright (UMBC) for his contributions to the database and query design. 
a publication in this particular study was counted whenever a researcher published in it or cited it.

\section{The Field of Neuroscience}

Neuroscientists seek to answer questions of how the nervous system, composed of the brain and the spinal cord, develops and functions. The study of brain and behavior is central to one goal of the biological sciences: to understand the basis of consciousness. At the molecular level, advances in genetic sequencing within the past two decades have revealed similarities between the types of proteins in the nervous system and the rest of the body. Therefore, a common framework for the study of cell biology and cellular neurobiology emerged.

A second and more challenging step for neuroscience is to unify the study of behavior, or the science of the mind, with neural science, the science of the brain, to achieve a unified understanding of behavior. $^{2}$

During the 1990s, designated by Congress as the "Decade of the Brain," neuroscientists made progress toward both understanding the underpinnings of human behavior and curing or preventing neurological disorders. ${ }^{3}$ Those involved in neuroscience at the molecular level have identified genes that play a role in the development of neurodegenerative disorders such as Alzheimer's and Huntington's diseases.

Neuroscience began to emerge as a unified discipline within the past few decades. ${ }^{4}$ Modern neuroscience is a multidisciplinary research field based on knowledge about the brain and behavior acquired from the distinct empirical traditions of molecular biology, neurophysiology, anatomy, embryology, cell biology, and psychology. 5,6

\section{Background}

In 2002, librarians at the University of Maryland conducted a triennial serials review one year earlier than usual to meet state budget shortfalls for fiscal year 2004 .
Each subject specialist librarian manages one or more serial funds to support the research and teaching of an academic department, with each fund tied to a particular department. Publications that support the needs of NACS researchers proved especially challenging because they are dispersed among multiple serial funds under the management of more than one librarian. A serials review of this magnitude required identification and understanding of the literature used by researchers in this field, which is what this study undertakes.

\section{Goals and Research Questions}

Four major research goals drove this case study:

1. Identify the literature supporting campus programs in neuroscience and cognitive science using citation analysis methodology. Assess the importance of the literature to the users according to three criteria:

- Type: Journals, monographs, conference papers, textbooks, annual reviews, review articles, etc. Is the population citing overwhelmingly from journals or other types of publications?

- Subject classification: Are the population's citations concentrated in one or more disciplines, or are they dispersed across many disciplines?

- Currency: How old are the journal articles cited?

2. Identify the journals in which the NACS community most frequently published and those they cited. Is there a great variation between the literature in which they publish and cite? Which subject disciplines do they cite? The ultimate goal was to identify journal titles of the highest importance to the NACS community for which subscriptions should be maintained.

3. Determine the citation interval, or number of years, between the publication date of papers authored by NACS researchers and the dates of each item in their bibliographies in order to assess their needs for newer and older literature. 
4. Identify the coauthorship patterns of NACS authors. Are researchers partnering more frequently with researchers from the NACS program, from other campus departments, or from outside the University of Maryland? To supplement the citation analysis methodology, an understanding of coauthorship patterns, especially among members from different departments, can explain the degree to which NACS researchers engage in interdisciplinary work.

\section{Related Research}

In the various forms of citation analysis, the usual goal is to identify publications cited by a certain population under the assumption that the earlier works cited guided and influenced the work of the contemporary authors. One important use of citation analysis is to identify the core journals of a discipline. Eugene Garfield described the earliest citation analysis study specific to neuroscience at a time when the field was still emerging, but already growing at a phenomenal rate. ${ }^{7}$ This early study highlighted the broad interdisciplinarity of journal literature cited by neuroscientists.

Citation analysis studies may be global or local in scope. In his global citation analysis study, Steve Black examined all the citations in every issue of a particular journal for a three-year period in order to identify a core collection in communication disorders. ${ }^{8}$ Chad E. Buckley used citation analysis to identify a core collection of biology monographs. ${ }^{9}$ Paul Kelsey and Tom Diamond focused their citation analysis on identifying core journals in the interdisciplinary field of forestry. ${ }^{10}$ Louise S. Zipp described the challenge of identifying a core list of journals for environmental geology, a specialty area of knowledge within the larger fields of environmental science and geology. ${ }^{11}$

Janice Kreider attempted to compare global analyses from ISI's Journal Citation Reports (JCR) with local citation data for the University of British Columbia for twenty subject fields in the sciences and social sciences. She found a strong correlation between the JCR data and the local data, at least for the most-cited items. The correlation grew much weaker and therefore much less useful, however, for less-cited items. ${ }^{12}$ Stanley J. Wilder also concluded that using JCR data available on the ISI Web site, in a formula he called the Estimated Annual Citation Rate (EACR), provided a relatively easy method for identifying the core journals in a field. ${ }^{13}$

Our local citation analysis is modeled largely on the study by Julie M. Hurd, Deborah D. Blecic, and Rama Vishwanatham, which examined the information needs of a small population of molecular biologists. ${ }^{14}$ They analyzed journal article citations of faculty members within the prior three years and reported on the total number of journals cited and their subject disciplines, formats of cited references, most-cited journals, and age distribution of molecular biology citations. The authors discussed their findings in a decision-making context for collection management and public services.

Earlier, Janet Hughes used citation data and other measures to identify a core list of molecular and cellular biology journals at Pennsylvania State University. ${ }^{15} \mathrm{Her}$ study, like this one, was driven by the library's larger serials review process. Rosalind Walcott also faced a substantial serials cut. ${ }^{16}$ She used a sample of citations from local dissertations and theses in biology to determine the types of literature cited (almost 92\% were journal articles), language dispersion (98\% were works written in English), time span (50\% of works cited were five years or less older than citing works and those published in the previous 10 years accounted for $80 \%$ of citations). Similarly, Margaret J. Sylvia studied the citations in student research papers to determine which journals were used most heavily and which ones were candidates for cancellation. ${ }^{17}$ Wallace Koehler sketched some pitfalls in relying on the accuracy and validity of ISI's citation data. ${ }^{18}$ 
Using a number of citation analysis techniques, these studies laid the groundwork for analyzing publications cited by researchers in various fields. This case study, however, attempts to examine the literature used by a self-defined multidisciplinary group in order to assess their needs and inform the collection management practices at the University of Maryland Libraries.

\section{Methodology}

\section{Identifying the NACS Population}

Research areas, teaching, and departmental affiliations for the 105 faculty and doctoral student members of NACS were gleaned from the program's Web site. ${ }^{19}$ Departments with the largest number of affiliations in the NACS program are biology and psychology. (See table 1.) Key areas of faculty research represented on the NACS Web site are: auditory neuroscience; cellular, molecular, and developmental neuroscience; foundations of cognitive science; human development; memory; decision making; reasoning; network models and pattern recognition; neuroethology; neuromorphic engineering and sensory-motor integration, and speech and language.

This case study included both faculty and graduate students in the population. Faculty members were limited to only those with a full-time appointment and the institutional address of University of Maryland, College Park (UMCP). Thus, the publications of seventy-eight faculty members and twenty-seven graduate students representing thirteen different departments were considered for analysis in this study. The decision to include graduate students was influenced by Hughes as she noted that graduate students may be in more need of library materials than faculty and that their work represents the most current trends in the research, which helps inform library decisions about collecting journals. ${ }^{20}$

\section{Using Citation Analysis to Identify Sup- porting Literature in Neuroscience}

To identify supporting literature in neuroscience and cognitive science, the

\begin{tabular}{|l|c|c|c|}
\hline \multicolumn{5}{|c|}{ TABLE 1 } \\
\hline Department Affiliations of NACS Faculty and Graduate Students \\
\hline Department & $\begin{array}{c}\text { Number } \\
\text { of Faculty } \\
\text { Members }\end{array}$ & $\begin{array}{c}\text { Number of } \\
\text { Graduate } \\
\text { Students }\end{array}$ & $\begin{array}{c}\text { No. of Faculty and } \\
\text { Graduate Students Who } \\
\text { Published in 2001-03 }\end{array}$ \\
\hline Animal and avian sciences & 6 & 0 & 3 \\
\hline Biology & 11 & 15 & 14 \\
\hline Chemistry \& biochemistry & 1 & 0 & 0 \\
\hline Computer sciences & 7 & 2 & 2 \\
\hline Electrical \& computer engineering & 7 & 1 & 5 \\
\hline English & 4 & 0 & 0 \\
\hline Hearing \& speech & 6 & 1 & 5 \\
\hline Human development & 3 & 0 & 2 \\
\hline Kinesiology & 4 & 2 & 3 \\
\hline Linguistics & 8 & 1 & 1 \\
\hline Nutrition and food science & 1 & 0 & 11 \\
\hline Philosophy & 7 & 1 & $\mathbf{5 3}(\mathbf{5 1 \% )}$ \\
\hline Psychology & 13 & 4 & $\mathbf{2 7}$ \\
\hline Total & $\mathbf{7 8}$ & & 6 \\
\hline
\end{tabular}


authors searched the online databases Science Citation Index and Social Science Citation Index for the journal publications of NACS faculty members and graduate students who published in the past three years (2001-2003) $(n=53)$. This study did not identify literature used by the NACS community in preparation of books or other publications not indexed in ISI. Nonetheless, it is unlikely that NACS authors relied on significant literature for this latter group of publications, but not for their journal articles indexed by ISI. Because not all NACS members publish in the field of neuroscience, the authors eliminated those articles that clearly fell outside the scope of neuroscience, as determined by article abstracts and keywords (e.g., "Characterizing quantum theory in terms of information-theoretic constraints"). In addition, articles about clinical applications rather than basic research (e.g., "treatment plans for stutterers") were eliminated. For each NACS author, the 2001-2003 neuroscience publications were saved in individual text files, named by the author's last name, and field delimited by author, title, source, keywords, abstract, addresses, and cited references. These files then were imported into a relational database in Microsoft Access to analyze two sets of data: the NACS authors' publications between 2001 and 2003 and the cited references for each of those articles.

A total of 170 articles were identified for the fifty-three NACS authors included in this study. For those articles, journal titles and the ISI subject categories associated with each journal were analyzed. The cited references for each article were analyzed by publication type. Then, the journal citations ( $n=6,270$ of the total 7,647 cited references) were analyzed by journal title and by subject class. Multiple occurrences of cited journal references were counted toward calculating the total number of cited references analyzed. The scope of this study included a total of 219 ISI subject categories, 122 of which occurred in the cited references analyzed.
When ISI assigned multiple subject headings to a journal title, all subject headings were counted.

Those sources that matched entries in the ISI master file were automatically assigned the type "journal." However, 22 percent of the cited references $(1,344$ records) listed the type as "unknown." This was for a variety of reasons. First, 284 records had typos, nonstandardized source abbreviations, or data omissions. Second, ISI had not indexed all cited reference source journals (which affected 153 records) and new records had to be created for them. This involved checking WorldCat and Ulrich's to identify the ISSN and assigning ISI subjects to the sources. The remaining cited reference sources (907 records) were not journals. To identify the type, the authors searched WorldCat and, as a last resort, checked the original article for a fuller citation. Finally, the coauthorship behavior of NACS authors was analyzed. This last task involved verifying the affiliation of all coauthors to determine whether or not each was a UMCP faculty member. If an individual was UMCP faculty, it was then determined whether he or she was a member of the same department as the NACS author and whether he or she was also a NACS member.

\section{Results and Discussion NACS Publications}

The 170 journal articles analyzed were published in 134 different journals. Table 2 shows the journals with the highest number of articles ranked first, with their respective ISI subject categories. Journals in which only one or two articles were published are not displayed in table 2 . For the period under study (2001-2003), NACS authors published in a broad spectrum of disciplines. The highest number of articles was published in the Journal of the Acoustical Society of America, which reflects the strong interest in the science of hearing among some members of the NACS community. Beyond the sixteen articles published in the Journal of the 


\begin{tabular}{|l|c|l|}
\hline \multicolumn{3}{|c|}{ TABLE 2} \\
\multicolumn{1}{|c|}{$\begin{array}{l}\text { Ranking of Journals by Number of Articles Published } \\
\text { by } \text { Nesearchers (n 170) }\end{array}$} \\
\hline \hline Journal Name & $\begin{array}{c}\text { No. of } \\
\text { Articles }\end{array}$ & \multicolumn{1}{c|}{ ISI Subject Category } \\
\hline $\begin{array}{l}\text { Journal of The Acoustical Society of } \\
\text { America }\end{array}$ & 16 & Acoustics \\
\hline Applied Psycholinguistics & 6 & Applied Linguistics \\
\hline Journal of Neurophysiology & 6 & Neurosciences / Physiology \\
\hline Journal of Comparative Neurology & 4 & Zoology / Neurosciences \\
\hline Brain Behavior and Evolution & 4 & Behavioral Sciences / Neurosciences \\
\hline Experimental Brain Research & 4 & Neurosciences \\
\hline Hearing Research & 4 & Neurosciences / Otorhinolaryngology \\
\hline $\begin{array}{l}\text { Journal of Speech Language and } \\
\text { Hearing Research }\end{array}$ & 4 & Applied Linguistics \\
\hline Biological Cybernetics & 3 & Computer Science, Cybernetics \\
\hline Brain Research & 3 & Neurosciences \\
\hline Vision Research & 3 & Neurosciences / Ophthalmology \\
\hline Brain And Cognition & 3 & Neurosciences \\
\hline Journal of Fluency Disorders & 3 & Education, Special \\
\hline $\begin{array}{l}\text { Molecular and Cellular } \\
\text { Endocrinology }\end{array}$ & 3 & $\begin{array}{l}\text { Cell Biology / Endocrinology \& } \\
\text { Metabolism }\end{array}$ \\
\hline Biological Cybernetics & 3 & Neurosciences \\
\hline $\begin{array}{l}\text { Organizational Behavior and Human } \\
\text { Decision Processes }\end{array}$ & 3 & Psychology, Applied \\
\hline Poultry Science & 3 & Agriculture, Dairy \& Animal Science \\
\hline Physiology \& Behavior & 3 & Behavioral Sciences \\
\hline & & \\
\hline
\end{tabular}

Acoustical Society of America, the remaining articles are thinly dispersed among the other 133 journals. NACS authors published in journals specialized to particular fields such as acoustics, applied linguistics, and neurosciences more than they did in general science journals such as Nature or Science.

The ISI subject categories were analyzed for the journals in which the 170 NACS articles were published. Table 3 shows the ranking of subject categories by count of published articles. Neurosciences ranked as the most common subject; 69 out of the 170 articles (41\%) were classed neurosciences. Other ISI subjects with high rankings were acoustics, applied linguistics, behavioral sciences, and psychology. Although the data for journal ranking show a dispersal of publications across 134 journals, the subject ranking data show a much tighter clustering, especially under the subject category of neurosciences.

\section{NACS Cited References}

The publication format of the 7,647 cited references in the 170 published NACS articles was analyzed. Nine categories of materials were created: journal article, book, conference material (proceedings of meetings and symposia, paper presented, poster presented, abstract of paper presented), monographic series, 
miscellaneous (technical report, computer program, lab manual, specifications, kit, test, CD-ROM database), unpublished paper (manuscript, in press), thesis, serial, and reference book. Of those cited references, 82 percent were to journal articles, 8 percent to books, 5 percent to conference papers, 2 percent to monographic series, and 1 percent each to miscellaneous and unpublished. Other publication types each were less than one percent. NACS members included in this study cited journal articles at a lower rate than the molecular biologists in Hurd's study $(83 \%$ compared to $93 \%)$, but cited books ( $8 \%$ compared to $4 \%$ ) and conference papers ( $5 \%$ compared to $0.4 \%$ ) at a higher rate.

Neurosciences was the most commonly occurring subject category (26\%) for the cited articles. (See table 4.) NACS authors

\begin{tabular}{|c|c|c|c|}
\hline \multicolumn{4}{|c|}{$\begin{array}{c}\text { TABLE } 3 \\
\text { Ranking of ISI Subjects by Count of Articles }(n=170)\end{array}$} \\
\hline ISI Subject Category & $\begin{array}{c}\text { No. of } \\
\text { Articles }\end{array}$ & ISI Subject Category & $\begin{array}{l}\text { No. of } \\
\text { Articles }\end{array}$ \\
\hline Neurosciences & 69 & Neuroimaging & 3 \\
\hline Acoustics & 18 & Psychology, Educational & 3 \\
\hline Applied Linguistics & 14 & Cell Biology & 3 \\
\hline Behavioral Sciences & 12 & Communication & 2 \\
\hline Psychology & 11 & \multirow{2}{*}{$\begin{array}{l}\text { Computer Science, Interdisci- } \\
\text { plinary Applications }\end{array}$} & \multirow[t]{2}{*}{2} \\
\hline Endocrinology \& Metabolism & 9 & & \\
\hline Physiology & 8 & Biology & 2 \\
\hline Zoology & 7 & Psychology, Mathematical & 2 \\
\hline \multirow{2}{*}{$\begin{array}{l}\text { Computer Science, Artificial } \\
\text { Intelligence }\end{array}$} & \multirow[t]{2}{*}{7} & Genetics \& Heredity & 2 \\
\hline & & Geriatrics \& Gerontology & 2 \\
\hline Otorhinolaryngology & 6 & \multirow{2}{*}{$\begin{array}{l}\text { Mathematics, Interdisciplinary } \\
\text { Applications }\end{array}$} & \multirow[t]{2}{*}{2} \\
\hline Ophthalmology & 5 & & \\
\hline Psychology, Applied & 5 & Nutrition \& Dietetics & 2 \\
\hline Psychology, Experimental & 5 & Pediatrics & 2 \\
\hline \multirow{2}{*}{$\begin{array}{l}\text { Agriculture, Dairy \& Animal } \\
\text { Science }\end{array}$} & \multirow[t]{2}{*}{4} & Engineering, Biomedical & 2 \\
\hline & & Robotics & 2 \\
\hline Clinical Neurology & 3 & Toxicology & 1 \\
\hline \multirow{2}{*}{$\begin{array}{l}\text { Engineering, Electrical \& } \\
\text { Electronic }\end{array}$} & \multirow[t]{2}{*}{3} & Telecommunications & 1 \\
\hline & & \multirow{2}{*}{$\begin{array}{l}\text { Radiology, Nuclear Medicine } \\
\text { \& Medical Imaging }\end{array}$} & \multirow[t]{2}{*}{1} \\
\hline Education, Special & 3 & & \\
\hline Developmental Biology & 3 & \multirow{2}{*}{$\begin{array}{l}\text { Public, Environmental \& Oc- } \\
\text { cupational Health }\end{array}$} & \multirow[t]{2}{*}{1} \\
\hline Computer Science, Cybernetics & 3 & & \\
\hline Sport Sciences & 3 & Multidisciplinary Sciences & 1 \\
\hline Psychology, Developmental & 3 & Psychology, Multidisciplinary & 1 \\
\hline Psychiatry & 3 & Environmental Sciences & 1 \\
\hline Biophysics & 3 & Psychology, Social & 1 \\
\hline $\begin{array}{l}\text { Biochemistry \& Molecular } \\
\text { Biology }\end{array}$ & 3 & & \\
\hline
\end{tabular}


cited the literature that was classed as zoology and physiology, both subsets of biological sciences, six percent of the time each, and psychology, multidisciplinary sciences, and behavioral sciences, each five percent of the time. ISI subjects used less than one percent of the time are not included in table 4.

Table 5 shows the ranked order of journals cited. Only journals with fifty or more cites are displayed. For the most popular journal, Journal of the Acoustical Society of America, a parallel trend emerges between publication and citation data. Although this journal ranks highest among journals in which NACS authors published and also among those they cited, the subject category of acoustics ranks far below neurosciences. Out of the 170 NACS articles analyzed, 41 percent were classed in neurosciences (table 2) and 26 percent of the journals cited were classed in neurosciences (table 4). Only about 10 percent of published NACS articles (table 3) and 4 percent of journals cited (table 5) were classed in acoustics. The fact that many journals have a secondary subject of neurosciences may have contributed to this result.

A comparison of tables 2 and 5 shows that of the top ten journals in which NACS authors published and cited from 2001 to 2003, five titles were the same. Again, Journal of the Acoustical Society of America occupies the top spot in both the publications and citations of NACS authors. Other journals appearing in both the top ten published in and cited journals are Journal of Neurophysiology, Journal of Comparative Neurology, Hearing Research, and Brain Research. Note that the multidisciplinary nature of the field precludes any one journal from dominating as a source of citations. The highest-ranked journal, Journal of the Acoustical Society of America, has only six percent of the total citations. Note also that the three general science journals in table 5 (Science, Nature, and Proceedings of the $\mathrm{Na}$ tional Academy of Sciences) are the three that Carolyn Virginia Mills identified in 1993 as the most important general science journals in molecular and cellular neurosciences. ${ }^{21}$ 


\section{Time Interval between Published Articles and Cited References for Journals}

The authors calculated the time interval between each NACS published article and each of its journal references. Out of the total 6,270 citations, the largest number $(3,635)$ was to materials up to ten years old. (See figure 1.)

Unlike Hurd, Blecic, and Vishwanatham's finding that molecular biologists tend to cite recent journal literature $(58 \%$ of cited material was five years old or less at time of publication of the citing article), this study's finding is that NACS authors cite more of the older literature. Only 33 percent of cited material in this study was five years old or less, and 54 percent of the cited material was nine years old or less. Compared to molecular biologists, neuroscientists are more likely to build on older work. In fact, almost 30 percent of all material cited $(1,825$ citations) was to articles fifteen years or older, and 8 out of 6,269 citations were to publications 90 to 107 years old. The variability of publication lag in different disciplines has been noted in previous studies. ${ }^{22}$ That neuroscientists cite much older literature than molecular biologists is not surprising because the study of the brain predates the discovery of DNA by centuries. Alcmaeon, student of Pythagoras, conceived the brain rather than the heart as the seat of intellect as early as the sixth century B.C., and this has been irrefutable since the nineteenth century. ${ }^{23}$ The findings of this study also corroborate the work of E. J. Rinia et al., who found that citation time interval varies by discipline and the degree to which the field of study is multidisciplinary. They found that the time interval between articles and their references is shorter for

\begin{tabular}{|c|c|}
\hline \multicolumn{2}{|c|}{$\begin{array}{c}\text { TABLE } 5 \\
\text { Ranked Order of Journals Cited } \\
\text { by NACS Authors ( }=6,270 \text { Citations } \\
\text { to } 786 \text { Journals })\end{array}$} \\
\hline Journal Name & $\begin{array}{c}\text { No. of } \\
\text { Journal } \\
\text { Citations } \\
\end{array}$ \\
\hline $\begin{array}{l}\text { Journal of The Acoustical Society of } \\
\text { America }\end{array}$ & $348(6 \%)$ \\
\hline Journal of Comparative Neurology & $297(5 \%)$ \\
\hline Journal of Neuroscience & $270(4 \%)$ \\
\hline Journal of Neurophysiology & $195(3 \%)$ \\
\hline Science & $155(35 \%)$ \\
\hline Hearing Research & $145(2 \%)$ \\
\hline Nature & $127(2 \%)$ \\
\hline Brain Research & $117(2 \%)$ \\
\hline $\begin{array}{l}\text { Proceedings of the National Academy } \\
\text { of Sciences of the United States of } \\
\text { America }\end{array}$ & $112(2 \%)$ \\
\hline Child Development & $99(2 \%)$ \\
\hline $\begin{array}{l}\text { Journal of Comparative Physiology } \\
\text { A-neuroethology Sensory Neural and } \\
\text { Behavioral Physiology }\end{array}$ & $88(1 \%)$ \\
\hline Experimental Brain Research & $88(1 \%)$ \\
\hline $\begin{array}{l}\text { Electroencephalography \& Clinical } \\
\text { Neurophysiology }\end{array}$ & $77(1 \%)$ \\
\hline Endocrinology & $75(1 \%)$ \\
\hline $\begin{array}{l}\text { Journal of Speech Language and } \\
\text { Hearing Research }\end{array}$ & $68(1 \%)$ \\
\hline Psychophysiology & $65(1 \%)$ \\
\hline $\begin{array}{l}\text { General and Comparative } \\
\text { Endocrinology }\end{array}$ & $57(1 \%)$ \\
\hline Vision Research & $57(1 \%)$ \\
\hline Neuron & $52(1 \%)$ \\
\hline Brain Behavior and Evolution & $50(1 \%)$ \\
\hline Developmental Psychology & $50(1 \%)$ \\
\hline
\end{tabular}

individual disciplines than for fields that are more multidisciplinary, at least in the life sciences, computer sciences, materials sciences, and pharmacology. Given the multidisciplinary nature of neuroscience, it is not surprising that neuroscience research has longer time intervals than 


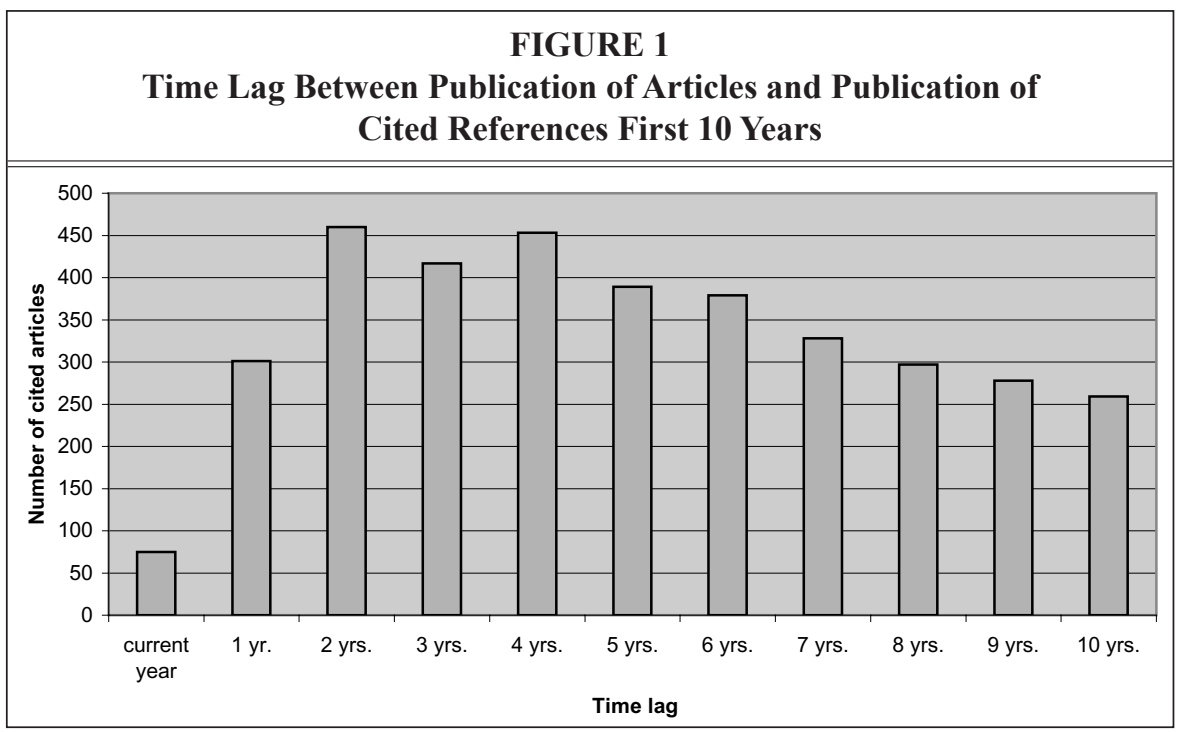

research within a single discipline such as molecular biology. ${ }^{24}$

\section{Coauthorship Patterns of NACS authors}

Previous studies have noted a systematic increase in collaboration on scholarly publications, although the extent to which researchers collaborate in their work and coauthor publications varies markedly by discipline. ${ }^{25}$ In general, researchers in the sciences collaborate more than in the social sciences, and even more so than in the humanities. Even within the sciences, however, studies such as that of M. E. J. Newman have shown variations in the average number of collaborators per published document. Newman found that biologists have four times as many collaborators as mathematicians. ${ }^{26}$

This study afforded the opportunity to investigate patterns of coauthorship among neuroscientists. The NACS community holds weekly colloquia in which NACS members and invited outside speakers share research related to neuroscience and cognitive science. Thus, many opportunities exist to exchange ideas. The authors of this study were interested in the degree to which NACS members took the opportunity to initiate research with each other and especially to cross departmental lines in the process.

Specifically, the authors asked four questions. First, because NACS membership represents departments that are classed as sciences, social sciences, as well as humanities, do researchers in this program follow the science pattern of frequent copublishing? The authors hypothesized that the experimental and multidisciplinary nature of the discipline would favor multiple authorship. The findings were that, indeed, a great deal of coauthorship occurred. Only 11 of 170 (6\%) NACS articles had single authorship, with no pattern favoring any particular discipline. NACS researchers follow the science pattern of a high degree of coauthoring.

Second, the authors were interested in the degree to which NACS members coauthor with faculty on the Maryland campus. Traditionally, coauthorship has been assumed to be a function of proximity; the closer geographically researchers are to each other, the likelier they are to coauthor. However, M. Sutter and M. Kocher discovered that in the field of economics, distance and other geographical variables are no longer predictors of collaboration. ${ }^{27}$ It appears that the ease 
of electronic communication widens the pool of colleagues and greatly facilitates long-distance coauthorship. Thus, the question for the authors of this study was whether local neuroscience coauthoring patterns would conform to traditional proximity patterns. The authors hypothesized that proximity and ease of contact would facilitate campus-internal coauthoring. Complex coauthoring patterns were found, with many articles authored by both campus and outside researchers. Articles with any Maryland coauthors were compared with those in which the NACS researcher coauthored exclusively with outside researchers. The results favored campus-internal coauthoring behavior, but given that articles written by both campus and outside coauthors were grouped with the campus researchers, the trend was not very strong: campusinternal coauthoring was 62 percent, and exclusively outside coauthoring was 38 percent. (See table 6.)

Third, the authors were most interested in finding out whether campusinternal coauthoring among NACS researchers was primarily with each other or with non-NACS researchers. Specifically, does shared membership in NACS and the sharing of research via colloquia foster a high degree of coauthoring? The patterns of NACS-internal coauthoring were complex. Three sets of coauthorship patterns were compared: (1) coauthoring exclusively with other NACS researchers; (2) coauthoring exclusively with UMCP colleagues who are not NACS members; and (3) coauthoring with both NACS members and UMCP non-NACS colleagues. (See table 6.) The results were surprising. NACS-only research accounted for only 10 percent, and NACS and non-NACS coauthorship accounted for 19 percent of the total University of Maryland coauthoring pattern. Thus, any NACS coauthoring only accounted for 29 percent of campus-internal coauthoring. NACS researchers coauthored with nonNACS researchers more than twice as

\begin{tabular}{|c|c|}
\hline \multicolumn{2}{|c|}{ TABLE 6 } \\
$\begin{array}{c}\text { Collaboration on NACS Coauthored } \\
\text { Journal Articles }(\mathbf{n}=\mathbf{1 5 9})\end{array}$ \\
\hline \hline Any UMCP collaboration & $98(62 \%)$ \\
\hline NACS only & $10(10 \%)$ \\
\hline Non-NACS only & $70(71 \%)$ \\
\hline NACS \& Non-NACS & $18(19 \%)$ \\
\hline Non-UMCP & $61(38 \%)$ \\
\hline
\end{tabular}

often (71\% of the time) as they did with fellow NACS members.

Finally, the authors wanted to know whether the NACS connection afforded more opportunity for interdepartmental cooperation than might otherwise be expected. The authors hypothesized that the NACS program would facilitate coauthoring opportunities between different departments. Even though NACS-internal coauthoring was less than anticipated, the authors were still interested in the extent to which coauthoring was not within a researcher's own department. The basis of comparison was any campus-internal NACS coauthoring with any campus-internal non-NACS coauthoring. Of the 28 instances of NACS coauthoring, $8(29 \%)$ included researchers from other departments, whereas only 13 of 88 instances $(15 \%)$ of non-NACS coauthoring included researchers from other departments. Though the numbers were not large, NACS researchers coauthored across departments about twice as often as non-NACS researchers. The hypothesis that membership in this multidisciplinary program fosters interdepartmental coauthoring was supported.

\section{Conclusions and Directions for Future Research}

During 2001-2003, NACS research at the University of Maryland was multidisciplinary. NACS authors' citing behavior crossed disciplinary lines to include the biological sciences, general and multidisciplinary sciences, and psychology and behavioral sciences. The ISI subject "neurosciences" constituted the highest 
number of both publications and cited references for NACS authors in this study. They primarily cited journal articles, with other materials such as books and conference publications ranking second and third, respectively. The authors identified a set of journals classed neurosciences in which NACS authors published and cited, respectively, in order to inform selection decisions. Those journal titles are presented in table 2 and 6 in ranked order.

Compared to the population of molecular biologists that Hurd et al. studied, NACS authors relied more on older literature. Nearly one-third of the material cited by NACS authors was fifteen years or older, and only one-third of the material cited by NACS authors was five years old or less. Future investigations could address the effect of exclusive use of online journals on neuroscientists' research.

Coauthorship patterns can reveal the degree to which a field is interdisciplinary. NACS researchers showed a high degree of co-authoring. The discovery that neuroscientists primarily submit coauthored research for publication follows the pattern of substantial collaboration in the sciences and increased collaboration in general. Although electronic communication allows a greater degree of longdistance coauthoring opportunities than in the past, UMCP neuroscientists still coauthor primarily with researchers on their own campus. This is reasonable because much of the experimental research reflects the use of highly specialized equipment and is associated with particu- lar labs. However, it is not clear why they coauthored with departmental colleagues more than with fellow NACS members. The NACS-specific patterns may be suggestive of any multidisciplinary group: while the group-internal coauthoring might be less than hoped for, one can still see an influence of the group in an increased amount of interdepartmental coauthoring.

It would be difficult for librarians at other institutions that offer neuroscience programs to use the data from this study unless graduate programs at their institutions are structured similarly to those at the University of Maryland. Graduate programs in neuroscience and neurobiology exhibit wide variability in structure and disciplinary focus, thus making it difficult to apply this study's findings directly to other institutional settings. ${ }^{28}$ However, the citation analysis methodology used in this study provides a model for librarians to identify the literature used by cross-departmental graduate programs in the neurosciences or other interdisciplinary fields. Although the primary methodology for this study was citation analysis, a more thorough investigation using coauthorship or collaboration patterns can be employed to fully explore the nature and degree of interdisciplinary work in neuroscience research in general, or within a particular area in it. Future investigators also may wish to broaden the scope of this case study to identify a more representative sample of the neuroscientist population than the NACS group at the University of Maryland.

\section{Notes}

1. Available online at http://www.umd.edu/NACS/.

2. Eric R. Kandel, James H. Schwartz, and Thomas M. Jessell, Principles of Neural Science, 4th ed. (New York: McGraw-Hill, Health Professions Division, 2000), 5.

3. Brain Facts: A Primer on the Brain and Nervous System, 4th ed. (Washington, D.C.: The Society for Neuroscience, 2000). Available online at http://web.sfn.org.

4. Society for Neuroscience (SfN) Web site: http://web.sfn.org.

5. The terms "multidisciplinary," "interdisciplinary," and "cross-disciplinary" are used inconsistently and somewhat interchangeably in the literature. For this study, the authors described neuroscience at the University of Maryland as "multidisciplinary," meaning that it involves more 
than two disciplines.

6. Kandel, Schwartz, and Jessell, Principles of Neural Science.

7. Eugene Garfield, "Using Citation Analysis to Study the Neuroscience Journals," Current Comments 41 (Oct., 1982): 5-14.

8. Steve Black, "Using Citation Analysis to Pursue a Core Collection of Journals for Communication Disorders," Library Resources \& Technical Service 45 (Jan. 2001): 3-9.

9. Chad E. Buckley, "Core Conservation Biology Monographs: A Citation Analysis," Reference Services Review 25 (fall/winter 1997): 147-59.

10. Paul Kelsey and Tom Diamond, "Establishing a Core List of Journals for Forestry: A Citation Analysis from Faculty at Southern Universities," College \& Research Libraries 64 (Sept. 2003): $357-77$.

11. Louise S. Zipp, "Core Serial Titles in an Interdisciplinary Field: The Case of Environmental Geology," Library Resources \& Technical Services 43(Jan.1999): 28-36.

12. Janice Kreider, "The Correlation of Local Citation Data with Citation Data from Journal Citation Reports," Library Resources \& Technical Services 43(Apr.1999): 67-77.

13. Stanley J. Wilder, "A Simple Method for Producing Core Scientific and Technical Journal Title Lists," Library Resources \& Technical Services 44(Apr. 2000): 92-96.

14. Julie M. Hurd, Deborah D. Blecic, and Rama Vishwanatham, "Information Use by Molecular Biologists: Implications for Library Collections and Services," College E Research Libraries 60 (Jan. 1999): 31-43.

15. Janet Hughes, “Use of Faculty Publication Lists and ISI Citation Data to Identify a Core List of Journals with Local Importance," Library Acquisitions: Practice \& Theory 19 (1995): 401-13.

16. Rosalind Walcott, "Local Citation Studies: A Shortcut to Local Knowledge," Science \& Technology Libraries 14 (1994): 1-14.

17. Margaret J. Sylvia, "Citation Analysis as an Unobtrusive Method for Journal Collection Evaluation Using Psychology Student Research Bibliographies," Collection Building 17 (1998): 20-28.

18. Wallace Koehler, "Nightmares in Citation Analysis," Reference \& User Services Quarterly 42 (fall 2002): 41-42.

19. Available online at http://www.nacs.umd.edu.

20. Hughes, "Use of Faculty Publication Lists and ISI Citation Data."

21. Carolyn Virginia Mills, "Library Materials in Molecular and Cellular Neuroscience," Science \& Technology Libraries 13 (spring/summer 1993): 57-70.

22. Ziming Liu, "Trends in Transforming Scholarly Communication and Their Implications," Information Processing \& Management 39 (Nov. 2003): 889-98.

23. Larry W. Swanson, Brain Architecture: Understanding the Basic Plan (Oxford: Oxford University Pr., 2003), 7.

24. E. J. Rinia, T. N. van Leeuwen, E. E. W. Bruins, et al., "Citation Delay in Interdisciplinary Knowledge Exchange," Scientometrics 51 (May 2001): 293-309.

25. Liu, "Trends in Transforming Scholarly Communication and Their Implications."

26. M. E. J. Newman, "Coauthorship Networks and Patterns of Scientific Collaboration," PNAS 101 (Apr. 2004): 5200-5205.

27. M. Sutter and M. Kocher, "Patterns of Co-Authorship among Economics Departments in the USA," Applied Economics 36 (Mar. 2004): 327-33.

28. Peterson's Graduate Programs in the Biological Sciences, 38th ed. (Princeton, N.J.: Thomson Peterson's, 2004). 


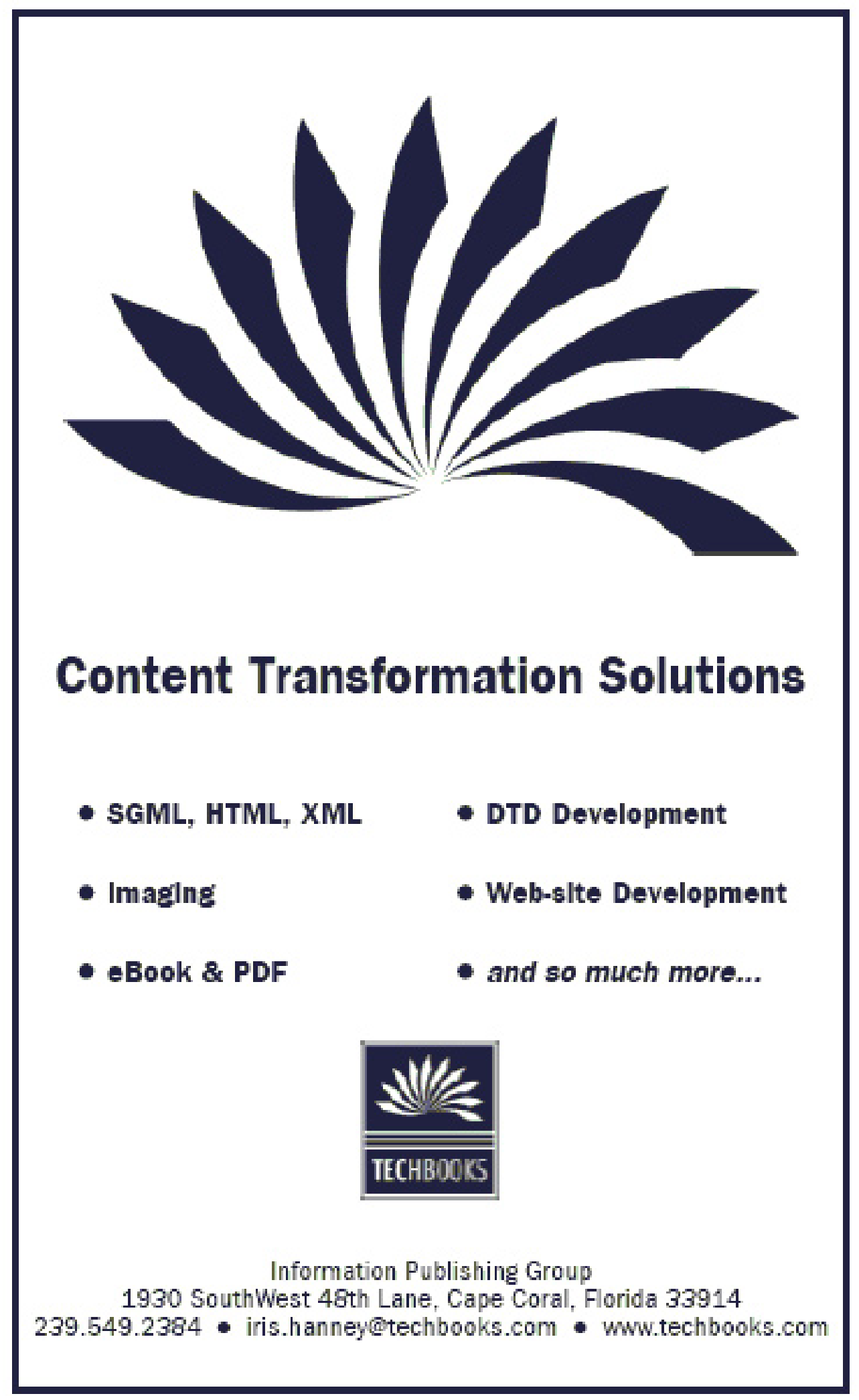

